\section{- OPEN ACCESS}

- Additional material is published online only. To view please visit the journal online (http://dx.doi.org/10.1136/ sextrans-2012-050979).

${ }^{1}$ HIV Key Populations Studies, Kenya Medical Research Institute, Kilifi, Kenya

${ }^{2}$ The Churchill Hospital, Oxford University Hospitals, Oxford, UK

${ }^{3}$ Institute Of Tropical \& Infectious Diseases, University of Nairobi, Nairobi, Kenya ${ }^{4}$ Department of Public Health, Oxford University, Oxford, UK ${ }^{5}$ Department of Medicine, University of Washington, Seattle, USA

${ }^{6}$ Nuffield Department of Clinical Medicine, Oxford University, Oxford, UK

\section{Correspondence to} Dr Peter Mwangi Mugo, HIV Key Populations Studies, KEMRI-Wellcome Trust Research Programme, P O Box 230, Kilifi 80108, Kenya; PMugo@kemri-wellcome.org

Received 17 December 2012 Revised 26 March 2013 Accepted 13 April 2013 Published Online First 22 May 2013

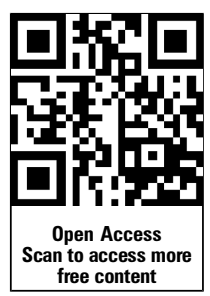

To cite: Mugo PM, Duncan S, Mwaniki SW, et al. Sex Transm Infect 2013;89:583-589.

\title{
Cross-sectional survey of treatment practices for urethritis at pharmacies, private clinics and government health facilities in coastal Kenya: many missed opportunities for HIV prevention
}

\author{
Peter M Mugo, ${ }^{1}$ Sarah Duncan, ${ }^{2}$ Samuel W Mwaniki, ${ }^{3}$ Alexander N Thiong ${ }^{\prime} 0,{ }^{1}$ \\ Evanson Gichuru, ${ }^{1}$ Haile Selassie Okuku, ${ }^{1}$ Elise M van der Elst, ${ }^{1}$ Adrian D Smith, ${ }^{4}$ \\ Susan M Graham, ${ }^{1,5}$ Eduard J Sanders ${ }^{1,6}$
}

\begin{abstract}
Background While bacterial sexually transmitted infections (STIs) are important cofactors for HIV transmission, STI control has received little attention in recent years. The aim of this study was to assess STI treatment and HIV testing referral practices among health providers in Kenya.

Methods In 2011 we assessed quality of case management for male urethritis at pharmacies, private clinics and government health facilities in coastal Kenya using simulated visits at pharmacies and interviews at pharmacies and health facilities. Quality was assessed using Ministry of Health guidelines.
\end{abstract}

Results Twenty (77\%) of 26 pharmacies, 20 (91\%) of 22 private clinics and all four government facilities in the study area took part. The median (IQR) number of adult urethritis cases per week was $5(2-10)$ at pharmacies, $3(1-3)$ at private clinics and $5(2-17)$ at government facilities. During simulated visits, $10 \%$ of pharmacies prescribed recommended antibiotics at recommended dosages and durations and, during interviews, $28 \%$ of pharmacies and $27 \%$ of health facilities prescribed recommended antibiotics at recommended dosages and durations. Most regimens were quinolone-based. HIV testing was recommended during $10 \%$ of simulated visits, $20 \%$ of pharmacy interviews and $25 \%$ of health facility interviews.

Conclusions In an area of high STI burden, most men with urethritis seek care at pharmacies and private clinics. Most providers do not comply with national guidelines and very few recommend HIV testing. In order to reduce the STI burden and mitigate HIV transmission, there is an urgent need for innovative dissemination of up-to-date guidelines and inclusion of all health providers in HIV/STI programmes.

\section{INTRODUCTION}

Chlamydia trachomatis (CT) and Neisseria gonorrhoeae (NG), the commonest causes of male urethritis, result in considerable morbidity and are important cofactors for HIV-1 transmission. ${ }^{1}{ }^{2}$ As sexually transmitted infections (STIs) enhance acquisition and transmission of HIV-1, STI treatment is important in HIV-1 prevention in its own right. Care-seeking for STIs presents an important opportunity to test for HIV-1, which is associated with STIs via sexual behaviour patterns. Thus, in a high HIV-1 prevalence setting such as Kenya, it is essential that people seeking care for STIs receive HIV-1 testing and high-quality STI treatment.

Pharmacies in resource-limited settings are often the first-and sometimes the only-point of contact for patients seeking urgent care owing to greater accessibility and patients' perception of increased privacy. ${ }^{3-5}$ Previous studies in sub-Saharan Africa and south-east Asia showed that, while the quality of STI care in pharmacies and other private providers was poor compared with government STI clinics, ${ }^{6-8}$ targeted interventions resulted in significant improvements. ${ }^{9-11}$

In Kenya the private health sector remains largely unregulated. ${ }^{12}$ A 2001 publication reported that the quality of STI care at pharmacies and private clinics was poor relative to government facilities, ${ }^{13}$ and a more recent study documented suboptimal care at pharmacies. ${ }^{14}$ There is no current information on how patients seeking care are targeted for HIV/STI prevention. No quality improvement interventions targeting pharmacies and private clinics have been evaluated in Kenya. The purpose of this study was to assess the current STI treatment and HIV testing referral practices in coastal Kenya, identifying potential areas for intervention.

\section{METHODS}

\section{Study setting}

The study was carried out in August and September 2011 in Mtwapa and Shanzu (total population 100 000), two townships located $16 \mathrm{~km}$ north-east of Mombasa along the principal highway connecting Mombasa to Malindi. The area is home to many bars and nightclubs frequented by male and female sex workers and is popular for beach tourism as well as transient stays by truckers and business people. During a mapping exercise conducted 2 weeks before the study, 22 private clinics, 4 government facilities and 26 private pharmacies were identified and GPS-way points taken (figure 1). In general, health facilities are operated by diploma-level clinical and nursing officers. They provide outpatient services including basic laboratory testing, medication dispensing, family planning, delivery, paediatric vaccinations and growth monitoring. Pharmacies are 


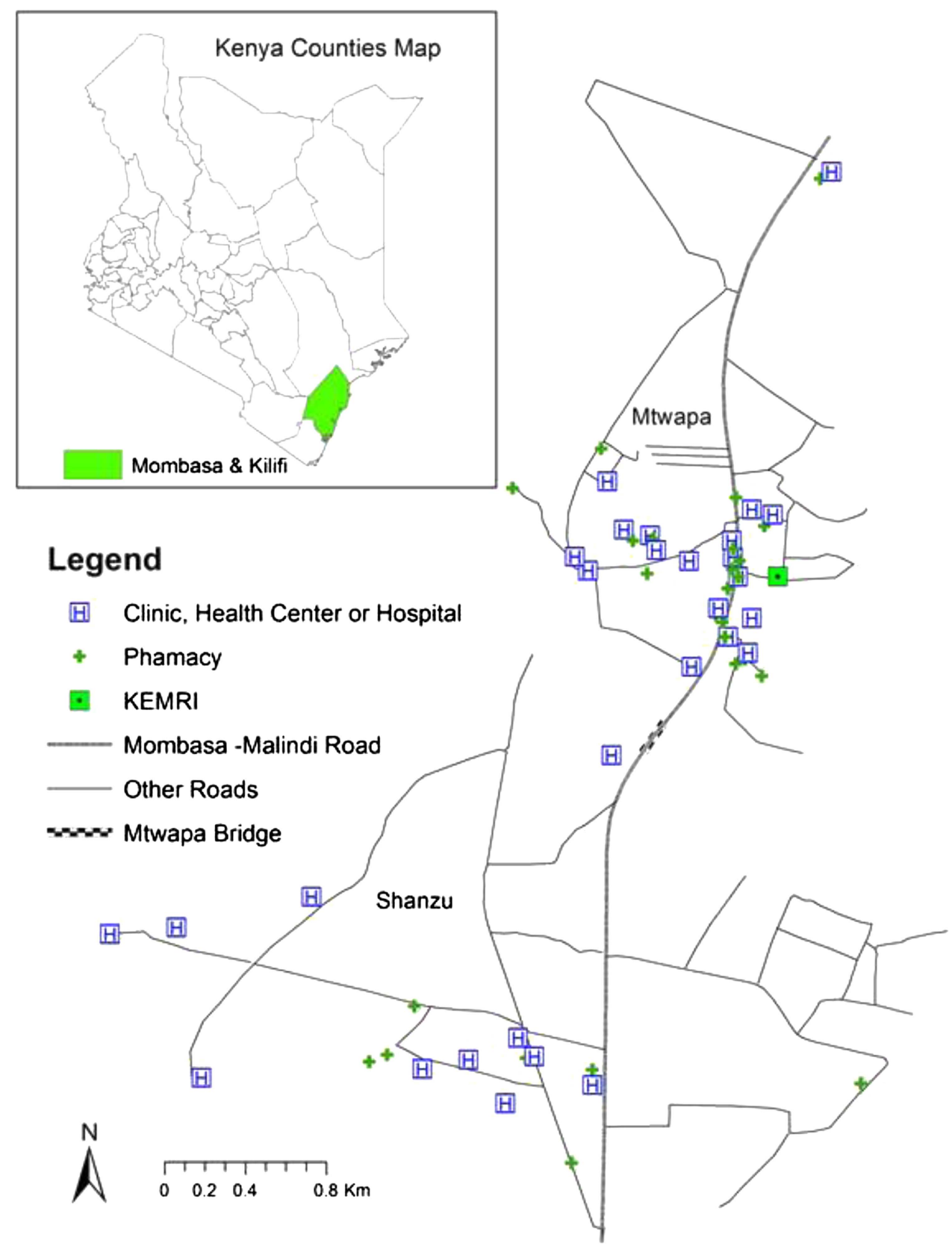

Figure 1 Pharmacies and health facilities in Mtwapa and Shanzu, coastal Kenya, 2011.

small to medium-sized businesses with at least one diploma-level pharmacy technician.

A Kenya Medical Research Institute (KEMRI) clinic in the area recruits at-risk adults, including men having sex with men (MSM) and female sex workers (FSWs), for HIV-1 prevention studies. STI diagnosis and treatment is provided to study participants. ${ }^{15} 16$ A high burden of asymptomatic CT and NG has been documented among MSM recently. ${ }^{17}$

\section{Data collection}

We invited all pharmacies and health facilities in the area to participate. Two methods of data collection were used: first we conducted simulated client visits at pharmacies and then, a week later, face-to-face interviews at pharmacies and health facilities. We did not send simulated clients to the health facilities because we felt it would be inappropriate to ask them to undergo physical examinations or laboratory testing. Pharmacies were asked for their consent the week before the simulated visits. We minimised bias by providing limited information on the purpose of the study: 'the advice and treatment offered to patients with STI symptoms'. Health facilities were asked for their consent just before the interviews to minimise bias.

\section{Simulated client visits}

In the first phase we trained four men aged 22-26 years as simulated clients to role play a case of acute uncomplicated male urethritis (figure 2). One simulated visit was made at each pharmacy. We gave simulated clients 200 Kenya shillings (KSh) per visit for purchase of medicines (US\$1 $\approx$ KSh 85 ). Approximately 10-20 min after each visit a brief closed-ended questionnaire (see online supplementary appendix 1) was administered to the simulated clients to collect data on the questions that the 


Statements:
"There is a fluid like pus coming from my penis... (thick yellow green discharge) ${ }^{*} \ldots$ I also feel pain when urinating
and also itchiness...Since the day before yesterday... (No other problems) ... (No such problem before) ... (Have
not seen a doctor yet)... (Had intercourse with someone I met in a club at night... about one week ago... a
woman)... (Did not use a condom)... what medicines can I buy for this problem? ... ([if referred] which
hospital/ clinic/ doctor should I go to?) ... what is the cost of the medicines? ... I do not have enough money ...
Please write down for me the remaining medicines and how much they will cost, so that I can look for money
to buy later ...
Notes:
1) Each paragraph in the full script was accompanied with a Kiswahili translation and the client was free to
switch between the languages, based on specific needs at each pharmacy.
2) Statements in round brackets were made only in response to questioning by pharmacy staff

Figure 2 Summarised script for a male urethritis case presented by simulated clients at pharmacies in Mtwapa and Shanzu, Kenya, 2011.

pharmacy staff had asked, medicines dispensed, cost of the medicines and advice given. Visits were unscheduled and they were all completed within 3 days. During a feedback meeting at the end of the study, none of the pharmacies reported being suspicious that the visit was simulated.

\section{Interviews}

In the second phase we interviewed one healthcare worker at each participating pharmacy and health facility. The questionnaire included both closed- and open-ended questions (see online supplementary appendices 2 and 3). Data collected included: health facility characteristics; male urethritis cases per week; interviewee characteristics; treatment for uncomplicated acute male urethritis; cost of treatment; interviewees' awareness of care seeking by FSWs and MSM; and challenges experienced in STI management. The interviews were unscheduled, except at a few very busy pharmacies where there was postponement to an agreed-upon time. The interviews lasted a median of $50 \mathrm{~min}$ (range 30-85).

\section{Main study outcome}

The main study outcome was the quality of urethritis case management assessed against current Kenyan Ministry of Health guidelines for syndromic STI treatment, which are based on WHO guidelines. ${ }^{18-20}$ Syndromic STI treatment, an approach developed in the 1990 s by the WHO, offers the opportunity to treat patients at the primary healthcare level, avoiding the need for laboratory capacity and highly trained healthcare providers. ${ }^{20}$

Quality elements were categorised into four groups:

(1) History of present illness: History-taking was considered adequate if it included nature and duration of symptoms, recent sexual exposure and previous care-seeking for current illness.

(2) Medication regimen compliance with guidelines: Regimens were considered compliant if they included at least one antibiotic to cover NG (amoxicillin $3 \mathrm{~g}$ in a single dose given immediately (stat) plus probenecid $1 \mathrm{~g}$ stat; amoxicillinclavulanate $625 \mathrm{mg}$ stat plus probenecid $1 \mathrm{~g}$ stat; cefixime $400 \mathrm{mg}$ stat; intramuscular ceftriaxone $250 \mathrm{mg}$ stat; intramuscular spectinomycin $2 \mathrm{~g}$ stat; ciprofloxacin $500 \mathrm{mg}$ stat; norfloxacin $800 \mathrm{mg}$ stat) and at least one to cover CT (doxycycline $100 \mathrm{mg}$ twice daily for 7 days; azithromycin $1 \mathrm{~g}$ stat).

(3) Potential treatment efficacy: Ideally, compliant antibiotics given and taken at the minimum recommended dosages and durations would be efficacious. However, for this study, quinolones and amoxicillins were considered ineffective given evidence of resistance. ${ }^{21-23}$ For CT, courses that were longer than recommended were assessed as potentially efficacious.

(4) Provision of counselling messages: Counselling was considered adequate if it included the following messages: 'get an HIV test', 'use condoms consistently', 'get partner treated' and 'adhere to the full course of treatment'.

\section{Data management and analysis}

Two investigators separately categorised responses to openended questions and differences were reconciled by a third investigator. Data from both phases of the study were doubleentered in Questionnaire Development System (Nova, Bethesda, Maryland, USA) and compared for agreement. All discrepancies were reconciled with the source before locking the database.

All statistical analyses were done using Stata (StataCorp, College Station, Texas, USA). Data from each simulated visit or interview were assumed to represent the treatment practices at that pharmacy or health facility. Interviewees who did not state their preferred regimens were excluded from the analyses of regimen compliance and efficacy. We calculated proportions for categorical data and medians or means for continuous or count data. Summary scores for history of present illness and provision of counselling messages were calculated, with one point being awarded for each element. Using a $\chi^{2}$ test or Fisher exact test for categorical data and a Student $t$ test or Wilcoxon rank-sum test for continuous or count data, characteristics and outcomes were compared between pharmacies and all health facilities, and between government and private facilities.

\section{RESULTS}

\section{Response rate}

Twenty (77\%) of 26 pharmacies, 20 (91\%) of 22 private facilities and all four government facilities in the study area took part. There were no differences in terms of size, location and opening hours between the private facilities and pharmacies that took part and those that did not. The main reason given for declining participation was lack of time.

\section{Characteristics of pharmacies and health facilities}

Table 1 details the characteristics of participating pharmacies and health facilities. Individually, government facilities reported seeing more cases of male urethritis per week than private facilities. 
Table 1 Characteristics of pharmacies and health facilities in Mtwapa and Shanzu, coastal Kenya, 2011

\begin{tabular}{|c|c|c|c|c|}
\hline \multirow[b]{3}{*}{ Characteristic } & \multirow{3}{*}{$\frac{\text { Pharmacies }(\mathrm{N}=20)}{\mathrm{N}(\%) \text { or median }(\mathrm{IQRt})}$} & \multicolumn{2}{|l|}{ Health facilities } & \multirow[b]{3}{*}{ p Value* } \\
\hline & & Private $(\mathrm{N}=20)$ & Government $(\mathrm{N}=4)$ & \\
\hline & & \multicolumn{2}{|c|}{$\mathrm{N}(\%)$ or median (IQRT) } & \\
\hline Total number of staff (including interviewees) $\ddagger$ & $2(1-3)$ & $4(3-6)$ & $22(16-30)$ & 0.03 \\
\hline \multicolumn{5}{|l|}{ Opening hours } \\
\hline Open 6 days per week (various hours) & $20(100 \%)$ & $19(95 \%)$ & $2(50 \%)$ & 0.01 \\
\hline Open 7 days per week (various hours) & $10(50 \%)$ & $17(85 \%)$ & $2(50 \%)$ & \\
\hline Open 7 days per week, $24 \mathrm{~h}$ daily & 0 & $13(65 \%)$ & $1(25 \%)$ & \\
\hline Mean opening hours per day & $13(12-14)$ & $24(13-24)$ & $9(8-17)$ & 0.04 \\
\hline \multicolumn{5}{|l|}{ Patient load } \\
\hline Total number of clients per day (all ages) & $60(30-100)$ & $10(10-15)$ & $183(90-350)$ & 0.03 \\
\hline Male urethritis cases per week & $5(2-10)$ & $3(1-3)$ & $5(2-17)$ & 0.03 \\
\hline \multicolumn{5}{|l|}{ Reference materials present } \\
\hline Formularies (Drug Index, BNF, MIMS Africa) & $17(85 \%)$ & $12(60 \%)$ & $1(25 \%)$ & \\
\hline Medical references & $6(30 \%)$ & $6(30 \%)$ & $1(25 \%)$ & \\
\hline STI guideline or flow chart & $1(5 \%)$ & $7(35 \%)$ & $2(50 \%)$ & \\
\hline Internet access (computer or mobile phone) & $15(75 \%)$ & $14(75 \%)$ & $3(75 \%)$ & \\
\hline \multicolumn{5}{|l|}{ Services relevant to STI/HIV management } \\
\hline HIV testing & 0 & 19 (95\%) & $4(100 \%)$ & \\
\hline HIV care services§ & 0 & $1(5 \%)$ & $4(100 \%)$ & $<0.001$ \\
\hline
\end{tabular}

Taken together, pharmacies, private clinics and government facilities reported seeing about 100, 60 and 20 cases of urethritis per week, respectively. The mean reported proportion of pharmacy clients presenting with prescriptions was $41 \%$. Eight (40\%) pharmacies reported having a private room for consultation.

\section{Characteristics of interviewees}

Apart from gender, there were no significant differences between private and government facility interviewees (table 2).
About $90 \%$ of all interviewees reported being aware that some of their clients could be FSWs and about one-third were aware that some of their clients could be MSM.

\section{Treatment strategies}

Medicines were dispensed at all simulated visits. When simulated clients said they did not have enough money, $12(60 \%)$ of 20 pharmacies dispensed partial courses of each medicine, four

Table 2 Characteristics of health workers interviewed during a study of treatment practices for urethritis in Mtwapa and Shanzu, coastal Kenya, 2011

\begin{tabular}{|c|c|c|c|}
\hline \multirow[b]{3}{*}{ Characteristic } & \multirow[b]{2}{*}{ Pharmacies $(\mathrm{N}=20)$} & \multicolumn{2}{|l|}{ Health facilities } \\
\hline & & Private $(\mathrm{N}=20)$ & Government $(\mathrm{N}=4)$ \\
\hline & $\overline{\mathrm{N}(\%) \text { or median }\left(\mathrm{IQR} \mathrm{R}^{\star}\right)}$ & $\mathrm{N}(\%)$ or median (IQR*) & \\
\hline \multicolumn{4}{|l|}{ Gender } \\
\hline Men & $10(50 \%)$ & $19(95 \%)$ & $1(25 \%)$ \\
\hline Women & $10(50 \%)$ & $1(5 \%)$ & $3(75 \%)$ \\
\hline Age (years) & $28(25-31)$ & $35(31-43)$ & $30(30-43)$ \\
\hline \multicolumn{4}{|l|}{ Highest level of health training attained $t$} \\
\hline Certificate & $5(26 \%)$ & $4(20 \%)$ & $1(25 \%)$ \\
\hline Diploma and higher diploma & $13(68 \%)$ & $13(65 \%)$ & $3(75 \%)$ \\
\hline Bachelor's degree & $1(5 \%)$ & $2(10 \%)$ & 0 \\
\hline Master's degree & 0 & $1(5 \%)$ & 0 \\
\hline Work experience (years) & $4(2-7)$ & $8(6-18)$ & $5(3-17)$ \\
\hline Membership in a professional association & $3(15 \%)$ & $14(70 \%)$ & $3(75 \%)$ \\
\hline Ever attended an in-service course on STI/HIV management & $2(10 \%)$ & $11(55 \%)$ & $2(50 \%)$ \\
\hline Duration of in-service course (days) & $5(3-7)$ & $5(2-7)$ & $4(2-5)$ \\
\hline Duration since the last course (years) & $6(2-10)$ & $5(3-9)$ & $8(3-12)$ \\
\hline
\end{tabular}


(20\%) dispensed fewer medicines and four (20\%) asked the client to come back with adequate funds.

During the interviews, when asked how they would manage an uncomplicated acute male urethritis case, 16 (80\%) of 20 interviewees at pharmacies said they would dispense medicines, two said they would dispense some medicines and then refer, and two said they would only refer. At health facilities, 17 (71\%) of 24 interviewees said they would treat based on symptoms and signs and seven (29\%) said they would treat based on laboratory results (ie, aetiologically). Five interviewees in the latter group stated the medications they would use for each suspected agent and were therefore included in the analysis of regimen compliance and efficacy.

\section{History of present illness}

Health facilities scored higher than pharmacies in history-taking (2.1 vs $1.6, p=0.03)$, mainly due to a difference in asking about recent sexual exposure (table 3 ).

\section{Medication regimen compliance with guidelines and potential treatment efficacy \\ Simulated client visits}

While $16(80 \%)$ of 20 pharmacies dispensed compliant antibiotics for NG (norfloxacin or ciprofloxacin), only $45 \%$ were at the recommended single dose (table 3); the rest were longer courses, including one 14-day course. With respect to CT treatment, while $85 \%$ of pharmacies dispensed a compliant antibiotic, only $10 \%$ were at the recommended dosage and duration (65\% dispensed too few doses and 15\% dispensed excessive doses). Overall, 25\% of pharmacies dispensed efficacious CT regimens (four doxycycline-based, one azithromycin-based), but none dispensed an efficacious NG regimen.
Interviews at pharmacies

Fourteen $(78 \%)$ of 18 pharmacies reported that they would prescribe a quinolone, $56 \%$ at the recommended dosage, and the rest would prescribe longer courses. Overall, eight (44\%) would prescribe efficacious CT regimens (five doxycycline-based, two azithromycin-based, one based on both antibiotics) but none would have prescribed an efficacious NG regimen.

\section{Interviews at health facilities}

There were no significant differences in regimen compliance or potential treatment efficacy between private and government health facilities. Sixteen $(73 \%)$ of 22 health facilities would prescribe compliant NG antibiotics (11 quinolones only; two quinolone plus ceftriaxone; one ceftriaxone only; one amoxicillin only; and one spectinomycin only). However, only $36 \%$ stated the right dosage. Overall, 36\% would prescribe efficacious CT regimens (seven doxycycline-based, one azithromycin-based), $14 \%$ would prescribe efficacious NG regimens (all ceftriaxonebased) and 9\% would effectively treat both agents.

\section{Provision of counselling messages}

Less than one-quarter of interviewees at pharmacies and private clinics and three-quarters at government facilities said they would recommend HIV-1 testing (table 3).

\section{Cost of treatment}

The median (IQR) cost of medicines dispensed during simulated visits was KSh350 (KSh175-623). During interviews, all pharmacies reported that consultation and dispensing were free of charge; the median (IQR) medication cost was KSh255 (KSh200-410). The median (IQR) consultation fee at health facilities was KSh100 (KSh20-200), KSh150 (KSh0-500) at private clinics and KSh20 (KSh10-20) at government facilities.

Table 3 Quality of male urethritis case management at pharmacies and health facilities in Mtwapa and Shanzu, Kenya, 2011

\begin{tabular}{|c|c|c|c|c|}
\hline \multirow[b]{3}{*}{ Quality elements assessed } & \multirow{3}{*}{$\begin{array}{l}\text { Simulated visits } \\
\text { Pharmacies } \\
(N=20) \\
N(\%) \text { or mean (SD) }\end{array}$} & \multicolumn{3}{|l|}{ Interviews } \\
\hline & & $\begin{array}{l}\text { Pharmacies } \\
(n=20)\end{array}$ & $\begin{array}{l}\text { Private health } \\
\text { facilities }(\mathrm{N}=20)\end{array}$ & $\begin{array}{l}\text { Government health } \\
\text { facilities }(\mathrm{N}=4)\end{array}$ \\
\hline & & \multicolumn{3}{|c|}{$\mathrm{N}(\%)$ or mean (SD) } \\
\hline \multicolumn{5}{|l|}{ History of present illness (HPI) } \\
\hline Nature and duration of symptoms & $20(100 \%)$ & $18(90 \%)$ & $16(80 \%)$ & $4(100 \%)$ \\
\hline Recent sexual exposure & $15(75 \%)$ & $9(45 \%)$ & $17(85 \%)$ & $1(25 \%)^{*}$ \\
\hline Previous care-seeking for current illness & $1(5 \%)$ & $6(30 \%)$ & $10(50 \%)$ & $3(75 \%)$ \\
\hline Summary HPI score (maximum 3) & $2(0.5)$ & $1.65(0.6)$ & $2.2(0.8)$ & $2.0(0.8)$ \\
\hline \multicolumn{5}{|l|}{ Medication regimens compliance $\ddagger \S$} \\
\hline Compliant regimen for gonorrhoea (right dosage and duration) & $9(45 \%)$ & $10(56 \%)$ & $7(39 \%)$ & $1(25 \%)$ \\
\hline Compliant regimen for Chlamydia (right dosage and duration) & $2(10 \%)$ & $5(28 \%)$ & $5(28 \%)$ & $2(50 \%)$ \\
\hline Compliant regimens for both gonorrhoea and Chlamydia (right dosage and duration) & $2(10 \%)$ & $5(28 \%)$ & $5(28 \%)$ & $1(25 \%)$ \\
\hline Potential treatment efficacy for both gonorrhoea and Chlamydia† & 0 & 0 & $2(11 \%)$ & 0 \\
\hline \multicolumn{5}{|l|}{ Provision of counselling messages } \\
\hline Get an HIV test & $2(10 \%)$ & $4(20 \%)$ & $3(15 \%)$ & $3(75 \%)^{*}$ \\
\hline Use condoms consistently & $12(60 \%)$ & $9(45 \%)$ & $13(65 \%)$ & $3(75 \%)$ \\
\hline Get partner treated & $13(65 \%)$ & $17(85 \%)$ & $16(80 \%)$ & $4(100 \%)$ \\
\hline Adhere to the full course of treatment & $19(95 \%)$ & $5(25 \%)$ & $10(50 \%)$ & $1(25 \%)$ \\
\hline Summary counselling score (maximum 4) & $2.3(1.3)$ & $1.8(0.9)$ & $2.1(0.9)$ & $2.8(1.0)$ \\
\hline
\end{tabular}


The median (IQR) medication cost at health facilities was KSh300 (KSh150-400), KSh300 (KSh190-500) at private clinics and zero at government facilities. The cost of ceftriaxonebased regimens was similar to other regimens. Cefixime was available at $65 \%$ of pharmacies and $17 \%$ of health facilities at a median (IQR) cost of KSh240 (KSh120-300).

\section{Challenges experienced in STI management}

The majority of interviewees reported difficulties in STI management (70\% of pharmacies and $83 \%$ of health facilities) including: clients not disclosing important history (36\%); inadequate or outdated information on STI management $(25 \%)$; patient non-adherence (23\%); inadequate diagnostic and referral facilities (14\%); and language barriers (9\%). Interviewees suggested that health provider training $(38 \%)$, patient education $(32 \%)$ and community education (18\%) would address some of these barriers.

\section{DISCUSSION}

Our study shows that most men with urethritis present to pharmacies and private clinics for care, that most healthcare providers do not provide nationally recommended or efficacious treatment, and that very few recommend HIV-1 testing. We also found that, unlike government facilities in the study area, most private clinics open for $24 \mathrm{~h}$ a day, every day of the week, thus offering the greatest service availability.

Our study achieved a high response rate, but we acknowledge that the results may suffer from some selection bias since not all eligible pharmacies and health facilities consented to participate and only one health worker was interviewed per facility. Additionally, since the study was conducted in two adjacent townships, the results may not be generalisable to the whole of coastal Kenya. Pharmacies reported that they did not suspect any of the simulated clients, and data obtained through simulated visits were largely comparable to interview data. Our interview procedures may therefore have avoided reporting bias. It is worth noting that pharmacies tended to perform better during simulated visits than in interviews, possibly due to a difference in question type. Our sample was relatively small, limiting our ability to identify associations between provider characteristics and treatment practices.

Similar to earlier studies, ${ }^{4-8} 111314$ we found that pharmacies and private clinics provide care for many adults with urethritis. Unlike previous studies in Kenya, we did not find significantly poorer quality of urethritis case management among pharmacies compared with health facilities, except in history-taking. However, this could be due to the small size of our sample or a difference in the definition of quality. Previous studies in Kenya did not assess service availability or specifically document if patients presenting with urethritis were targeted for HIV testing.

Our findings highlight the opportunity for HIV testing, counselling and referral that presents through the frequent STI careseeking at private clinics and pharmacies. This is particularly relevant considering recent advances in point-of-care testing technology, ${ }^{24}$ which could make it more feasible for frontline healthcare providers to recommend and carry out HIV testing in these settings.

We found that most health providers would treat a case of urethritis syndromically and most would include a quinolone as part of the regimen, implying they had some prior exposure to the current syndromic guidelines. However, the guidelines themselves were rarely available on site. Besides availability, we also note with concern that the Kenyan guidelines, ${ }^{18}{ }^{19}$ as well as the WHO guidelines, ${ }^{20}$ still recommend quinolones as a first- line regimen for syndromic treatment despite documented widespread NG resistance. ${ }^{21} 22$ We can only speculate that this failure to revise and disseminate new guidelines is due to a lack of priority given to keeping such documents up to date. Innovative strategies must be devised to ensure prompt updating and dissemination of guidelines. The STI control programme should borrow from other disease programmes that have successfully employed internet and mobile technologies. ${ }^{25}$

Since a majority of interviewees at health facilities and a minority at pharmacies reported being members of a professional association, continuing professional development programmes should aim to use as well as foster professional networks among trainees. As FSWs and MSM are being targeted for HIV prevention in Kenya and frequently seek care at health facilities and pharmacies, recently published guidelines on STI control among these key populations ${ }^{26} 27$ should be included in training programmes for health providers serving in similar settings.

In summary, we found that in an area of high STI burden, most patients with urethritis seek health care from pharmacies and private clinics, and that the treatment provided does not comply with guidelines. In order to reduce the STI and HIV burden, increase HIV testing uptake and enable timely linkage into care, pharmacies and private clinics should be more engaged in HIV/STI prevention programmes. Further research is required to enhance the development, revision and dissemination of guidelines on STI control.

\section{Key messages}

- In an area of high STI burden, most patients with urethritis seek healthcare from pharmacies and private clinics.

- Pharmacies and private clinics should be more engaged in upscaling HIV/STI prevention programmes.

- Healthcare provider compliance with recommended treatment regimens is low and HIV testing is infrequently recommended.

- Current guidelines still recommend quinolone-based STI regimens, which remain in use in Kenya despite the emergence of resistance.

Acknowledgements We thank the participating health facilities and pharmacies, the Provincial Director of Public Health and Sanitation-Coast and the men who acted as simulated clients. We thank all staff of the HIV Key Populations Studies Cluster of KWTRP-Kilifi, especially Elizabeth Wahome and Jennifer Kanungi. This report was published with permission from KEMRI. This study was presented in part at the 6th INTEREST conference in Mombasa in 2012 (abstract number P-14).

Contributors EJS and SD conceived the study. EJS, SD, ADS, SMG, EVDE, EG, HSO and PMM developed the protocol. PMM, SWM and ANT collected the data. PMM, EJS and HSO analysed the data. PMM prepared the draft manuscript. All authors reviewed and approved the final manuscript.

Funding This study received funding from the USA Agency for International Development (USAID) through the International AIDS Vaccine Initiative (IAVI). This work was made possible in part by the support of the American people. The contents are the responsibility of the study authors and do not necessarily reflect the views of USAID or the USA Government. This study also received funding from the Wellcome Trust, through KEMRI-Wellcome Trust Research Programme (KWTRP)Kilifi core funding (\#077092). SWM was funded by the University of Nairobi.

Competing interests None.

Ethics approval Ethical approval was granted by the KEMRI National Ethical Review Committee. Participants provided written informed consent for both study phases. No financial incentive was given for participation. Participant information 
was protected at all times through the use of identification numbers in place of names, and through restriction of access to completed consent forms.

Provenance and peer review Not commissioned; externally peer reviewed.

Open Access This is an Open Access article distributed in accordance with the Creative Commons Attribution Non Commercial (CC BY-NC 3.0) license, which permits others to distribute, remix, adapt, build upon this work non-commercially, and license their derivative works on different terms, provided the original work is properly cited and the use is non-commercial. See: http://creativecommons.org/ licenses/by-nc/3.0/

\section{REFERENCES}

1 Chen L, Jha P, Stirling B, et al. Sexual risk factors for HIV infection in early and advanced HIV epidemics in sub-Saharan Africa: systematic overview of 68 epidemiological studies. PLoS One 2007;2:e1001.

2 Hayes R, Watson-Jones D, Celum C, et al. Treatment of sexually transmitted infections for HIV prevention: end of the road or new beginning? AIDS 2010;24 (Suppl 4):S15-26

3 Voeten HA, O'Hara HB, Kusimba J, et al. Gender differences in health care-seeking behavior for sexually transmitted diseases: a population-based study in Nairobi, Kenya. Sex Transm Dis 2004;31:265-72.

4 Fonck K, Mwai C, Rakwar J, et al. Healthcare-seeking behavior and sexual behavio of patients with sexually transmitted diseases in Nairobi, Kenya. Sex Transm Dis 2001:28:367-71.

5 Moss W, Bentley M, Maman S, et al. Foundations for effective strategies to control sexually transmitted infections: voices from rural Kenya. AIDS Care 1999;11:95-113.

6 Leiva A, Shaw M, Paine $K$, et al. Management of sexually transmitted diseases in urban pharmacies in The Gambia. Int J STD AIDS 2001;12:444-52.

7 Somse P, Mberyo-Yaah F, Morency $P$, et al. Quality of sexually transmitted disease treatments in the formal and informal sectors of Bangui, Central African Republic. Sex Transm Dis 2000;27:458-64.

8 Chalker J, Chuc NT, Falkenberg T, et al. STD management by private pharmacies in Hanoi: practice and knowledge of drug sellers. Sex Transm Infect 2000;76:299-302.

9 Chalker J, Chuc NT, Falkenberg T, et al. Private pharmacies in Hanoi, Vietnam: a randomized trial of a 2-year multi-component intervention on knowledge and stated practice regarding ARI, STD and antibiotic/steroid requests. Trop Med Int Health 2002;7:803-10.

10 Garcia P, Hughes J, Carcamo C, et al. Training pharmacy workers in recognition, management, and prevention of STDs: district-randomized controlled trial. Bull World Health Organ 2003;81:806-14

11 Adu-Sarkodie Y, Steiner MJ, Attafuah J, et al. Syndromic management of urethral discharge in Ghanaian pharmacies. Sex Transm Infect 2000;76:439-42.
12 World Bank. Private Health Sector Assessment in Kenya. 2010, http://pdf.usaid.gov/ pdf_docs/PNADS739.pdf (accessed 28 Aug 2012).

13 Voeten HA, Otido JM, O'Hara HB, et al. Quality of sexually transmitted disease case management in Nairobi, Kenya: a comparison among different types of healthcare facilities. Sex Transm Dis 2001;28:633-42.

14 Kwena ZA, Sharma A, Muga C, et al. Management of simulated patients with sexually transmitted infections by staff of retail pharmacies in Kibera slums of Nairobi. East Afr Med J 2008:85:419-24.

15 Sanders EJ, Graham SM, Okuku HS, et al. HIV-1 infection in high risk men who have sex with men in Mombasa, Kenya. AIDS 2007;21:2513-20.

16 Grijsen ML, Graham SM, Mwangome M, et al. Screening for genital and anorectal sexually transmitted infections in HIV prevention trials in Africa. Sex Transm Infect 2008;84:364-70

17 Sanders EJ, Thiong'o AN, Okuku HS, et al. High prevalence of Chlamydia trachomatis and Neisseria gonorrhoeae infections among HIV-1 negative men who have sex with men in coastal Kenya. Sex Transm Infect 2010;86:440-1.

18 Kenya Ministry of Health. National guidelines for reproductive tract infection services. 2006. http://archive.k4health.org/system/files/National\%20guidelines\% 20for\%20RTI\%20services.pdf (accessed 3 Jul 2012).

19 Kenya Ministry of Health. Clinical management and referral guidelines. Volume II. 2009. http://chs.uonbi.ac.ke/sites/default/files/chs/chs/Clinical\%20Guidelines\%20Vo \%201I\%20Final.pdf (accessed 2 Jul 2012).

20 World Health Organization. Guidelines for the management of sexually transmitted infections. 2003. http://www.who.int/hiv/pub/sti/en/STIGuidelines2003.pdf (accessed 2 Jul 2012).

21 Duncan S, Thiong'o AN, Macharia $M$, et al. High prevalence of quinolone resistance in Neisseria gonorrhoeae in coastal Kenya. Sex Transm Infect 2011;87:231.

22 Lagace-Wiens PR, Duncan S, Kimani J, et al. Emergence of fluoroquinolone resistance in Neisseria gonorrhoeae isolates from four clinics in three regions of Kenya. Sex Transm Dis 2012;39:332-4.

23 Lind I. Antimicrobial resistance in Neisseria gonorrhoeae. Clin Infect Dis 1997;24 (Suppl 1):S93-7.

24 Tucker JD, Bien CH, Peeling RW. Point-of-care testing for sexually transmitted infections: recent advances and implications for disease control. Curr Opin Infect Dis 2013;26:73-9.

25 Zurovac D, Sudoi RK, Akhwale WS, et al. The effect of mobile phone text-message reminders on Kenyan health workers' adherence to malaria treatment guidelines: a cluster randomised trial. Lancet 2011;378:795-803.

26 World Health Organization. Prevention and treatment of HIV and other sexually transmitted infections among men who have sex with men and transgender people. 2011. http://whqlibdoc.who.int/publications/2011/9789241501750_eng.pdf (accessed Apr 2013).

27 Kenya Ministry of Health, National AIDS and STI Control Programme (NASCOP). National guidelines for HIV/STI programs for sex workers. 2010. http://www.nascop. or.ke (accessed Nov 2011). 